\title{
Mikro- und Makrowelten
}

Erhard Taverna
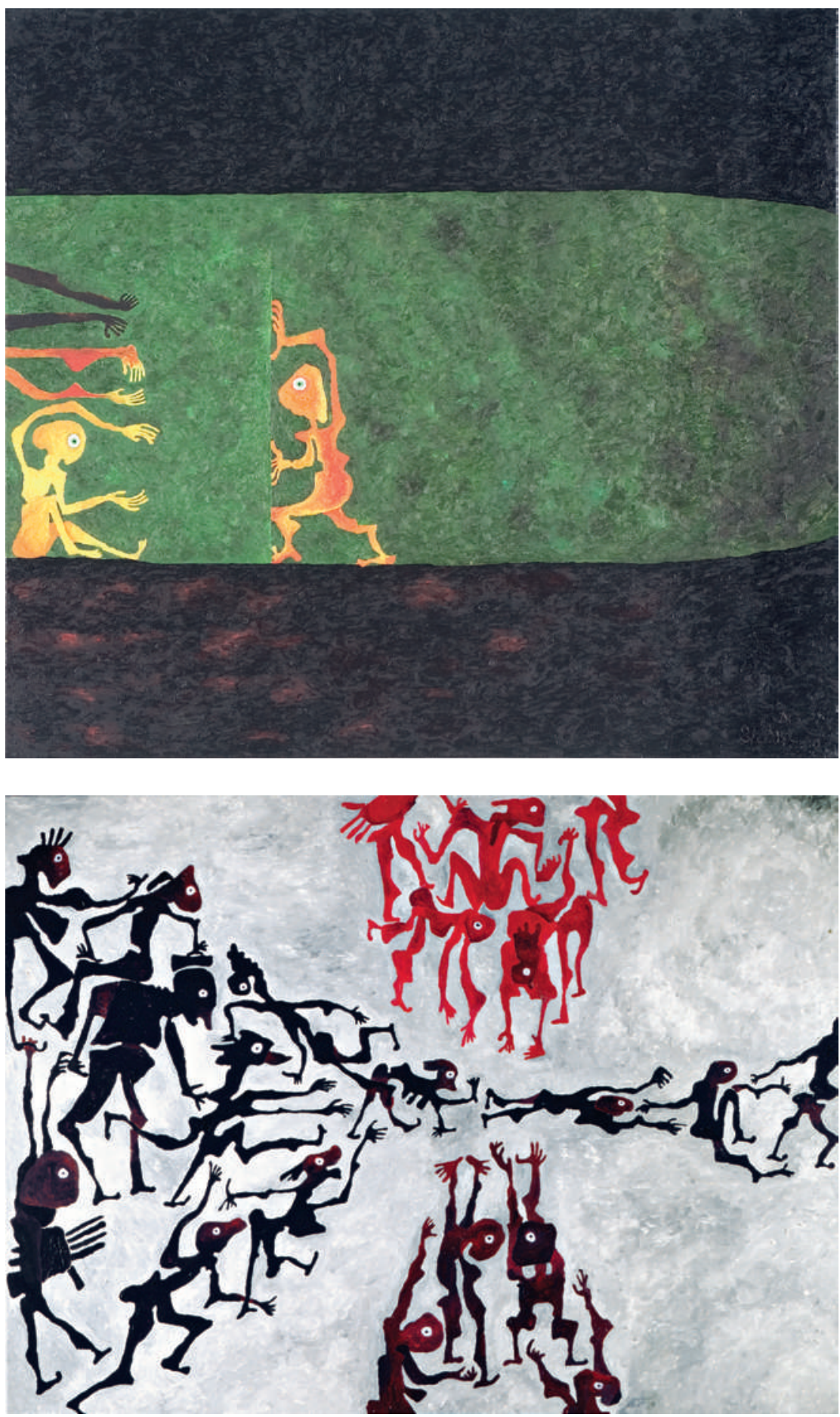

Der doppelt Begabte vereinigt Kunst und Wissenschaft zum unverkennbaren Stil. Seine Figürchen krabbeln wie Ameisen über die kräftig bunten Ölgemälde. Kleine Männchen streben in Gruppen und einzeln durch eine futuristische Welt leuchtender Abstraktionen, die an Träume und histologische Strukturen erinnern. Surrealistische Amöben, witzig, boshaft oder panisch auf der Flucht, immer in Bewegung, am Erklimmen, Abstürzen, Balancieren und im Gespräch. Vielgestaltige Comic-Klekse, unaufhörlich in Metamorphose, ausgesetzt in einer Welt aus aggressivem Rot, irritierendem Gelb, tiefem Blau, prallem Grün und beruhigendem Schwarz.

Prof. Dr. Diethard Gemsa, geboren 1937, studierte Medizin und besuchte nebenher die Hochschule für Bildende Kunst in Berlin. Dem Staatsexamen und der Promotion 1964 in Freiburg folgten erfolgreiche Forscherjahre in Seattle, San Francisco, Heidelberg, Hannover und schliesslich Marburg, wo er als Professor das Institut für Immunologie 21 Jahre lang leitete. In San Francisco war er für 3 Jahre in der Gastroenterologie und Immunologie der University of California bei seinem wichtigsten Lehrer und späteren Freund Rudi Schmid, dem «Bilirubinpapst» aus der Schweiz. "Alles, was Du schreibst, muss wie ein Gesetz sein», habe ihm dieser eingeschärft. Von Laborexperimenten mussten mindestens drei identische und keine abweichenden Resultate vorliegen, bevor die Fachwelt davon erfuhr. Diese verehrt denn auch den erfolgreichen Forscher, der unter anderem ein vielbeachtetes Lehrbuch zur Immunologie herausgab und für 25 Jahre Editor-in-Chief der Zeitschrift «Immunobiology» war.

Bereits der Vater, ein Chemiker, habe gemalt, er wollte aber nicht, dass sein Sohn daraus einen Brotberuf machte. Weil Medizin Ende der 50er Jahre unter angehenden Akademikern keinen guten Ruf hatte - «nur die mit den schlechtesten Abiturnoten studierten Medizin» - plante er erst ein Chemiestudium. Er vermisste aber den Kontakt zu Menschen und begann das Medizinstudium. Seit der Emeritierung reist Diethard Gemsa mehrmals jährlich für 2 bis 3 Wochen nach Jeddah in Saudi-Arabien, wo er am Batterjee Medical College Biochemie und Immunologie lehrt. Anfangs habe eine über zwei Meter hohe Trennwand im Hörsaal die weiblichen von den männlichen Hörern aus SaudiArabien, Pakistan, Syrien, Ägypten und den Emiraten getrennt. Seither sei die Wand immer niedriger geworden oder gar ganz verschwunden. Hätten zu Beginn noch fast alle Frauen den traditionellen 
Bilder von links oben nach rechts unten:

Ich wollte, $90 \times 100 \mathrm{~cm}$

Nadelöhr, $60 \times 80 \mathrm{~cm}$

Mögliches, $100 \times 120 \mathrm{~cm}$ Matrix, $80 \times 80 \mathrm{~cm}$
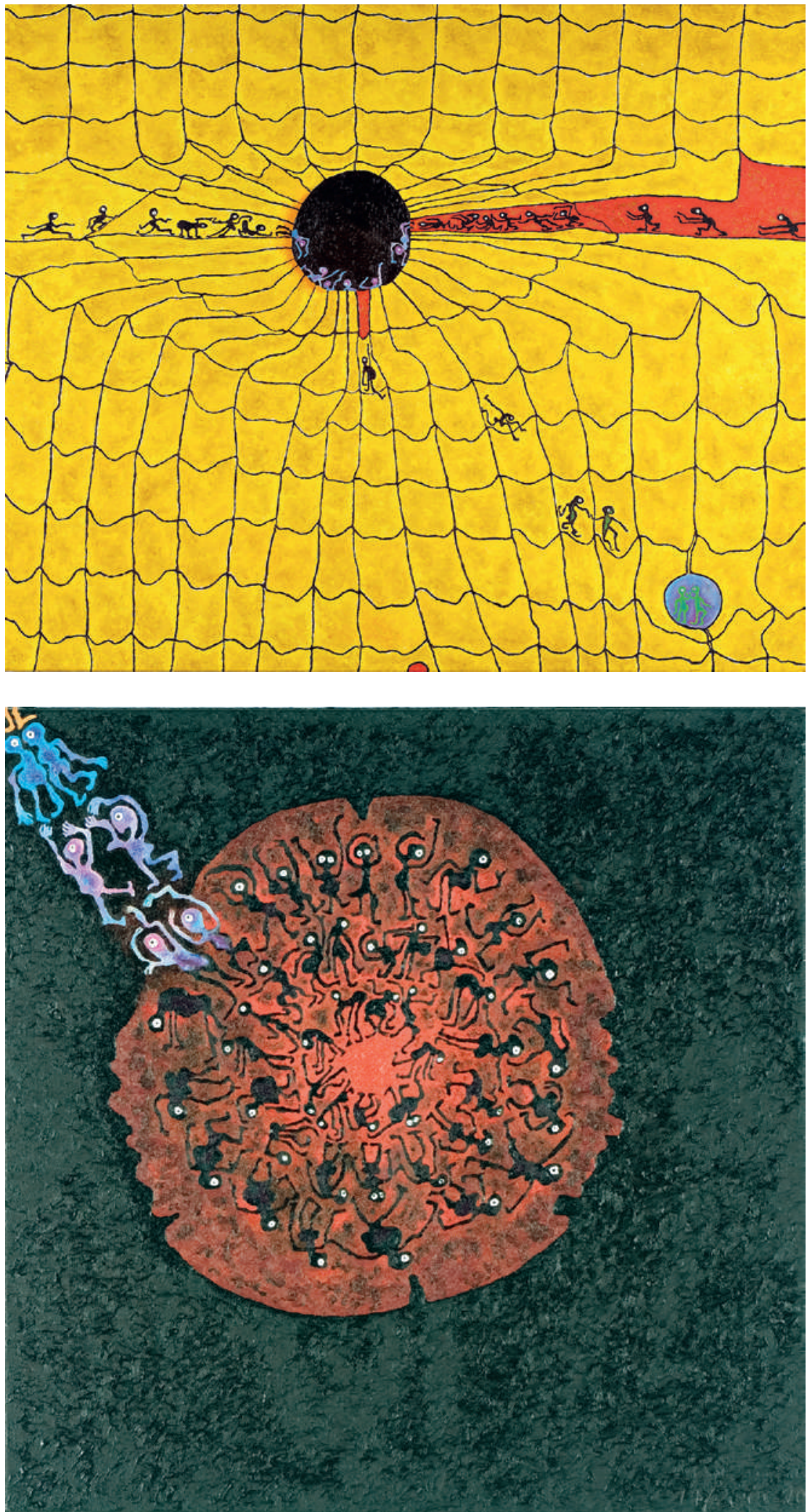

Niqab getragen, so sei das heute nur noch eine kleine Minderheit unter den zahlreichen Studentinnen.

Nach vielen Jahren als Institutsleiter, Fachgutachter der Deutschen Forschungsgesellschaft und Mitglied des Bewilligungsausschusses für Sonderforschungsbereiche ist das Malen, neben Ehefrau und drei Kindern, immer wichtiger geworden. Die Musik von Bach versetze ihn in eine meditative Gelassenheit, aus der heraus er die inneren Bilder in kürzester Zeit mit Bleistift vorskizziere. Visionen, Träume, abstrakte und figürliche Vorstellungen alltäglicher Themen, wie Trennung, Liebe, Schmerz und Verlassenheit. Der Drang zur Darstellung ist persönlich-politischer Natur, die Gestaltung orientiert sich an beruflichen Vor-Bildern aus der Arbeitswelt. Er sei immer ein visueller Denker gewesen. Die zellulären Strukturen der Ölgemälde erinnern an mikroskopische Vergrösserungen oder molekulare Abbilder. «Ich kann nicht immer sagen, was die Bilder bedeuten.» Viele Deutungen sind möglich, jeder Betrachter mag seine eigene Version haben. Die grossen Formate würden auch sehr gut in Praxis- und Klinikräume passen. In Deutschland gab es schon viele Ausstellungen, in der Schweiz waren die Werke erstmals in Zürich, in der Galerie «Kunst im West» zu sehen. 25 Gemälde, zu deren Vernissage der Kollege und Nobelpreisträger Rolf Zinkernagel eine Rede hielt. Doch heute ist Finissage. Ganz am Ende des Gesprächs kommt Ursula Koller-Lehner, die Gründerin der unabhängigen Kunstgalerie, und teilt dem Künstler mit, dass ein weiteres Bild verkauft sei. Auch das gehört zu einer richtigen Ausstellung.

\section{Weitere Informationen}

www.gemsakunst.de

Prof. Dr. med. Diethard Gemsa,

gemsa[at]staff.uni-marburg.de

Galerie «Kunst im West», Förrlibuckstrasse 62,

8005 Zürich www.kunstimwest.ch 